\title{
Physical and Motor Fitness, Sport Skills and Executive Function in Adolescents: A Moderated Prediction Model
}

\author{
Rosalba Marchetti ${ }^{1}$, Roberta Forte ${ }^{1}$, Marco Borzacchini'2, Spyridoula Vazou ${ }^{3}$, \\ Phillip D. Tomporowski ${ }^{4}$, Caterina Pesce ${ }^{1}$ \\ ${ }^{1}$ Human and Health Sciences, Department of Movement, University of Rome "Foro Italico", Roma, Italy \\ ${ }^{2}$ FISDIR, Italian Federation for Sport for Intellectual and Relational Disability, Roma, Italy \\ ${ }^{3}$ Department of Kinesiology, lowa State University, Ames, USA \\ ${ }^{4}$ Department of Kinesiology, University of Georgia, Athens, USA \\ Email: rosalba.marchetti@uniroma4.it,roberta.forte@uniroma4.it, caterina.pesce@uniroma4.it, \\ borzacchini@fisdir.it,svazou@iastate.edu,ptomporo@uga.edu
}

Received 16 September 2015; accepted 23 November 2015; published 26 November 2015

Copyright (C) 2015 by authors and Scientific Research Publishing Inc.

This work is licensed under the Creative Commons Attribution International License (CC BY). http://creativecommons.org/licenses/by/4.0/

(c) (i) Open Access

\section{Abstract}

Recent evidence suggests that fitness and sport expertise jointly benefit cognition and that expertise in cognitively demanding strategic sports enhances both domain-specific cognition and domain-general cognitive function, the executive. However, research focusing on whether physical and motor fitness and sport skill are independent determinants of executive function efficiency, or interact with each other is still lacking. The present study investigated this issue in adolescents. Four hundred and eleven boys and girls aged 12 to 15 years were recruited from Italian schools. They were tested for 1) physical fitness (cardiovascular fitness and muscle power); 2) motor control and perceptual-motor adaptation ability (kinaesthetic discrimination and response orientation ability); 3) core executive functions (inhibition and working memory updating); 4) game skills in team sport (decision making and support). While working memory updating was predicted only by physical fitness, inhibition was predicted by game skill, physical fitness and response orientation ability, and by the interaction of these latter ones. Fitness level significantly moderated the prediction accrued by response orientation ability, with inhibition predicted only in the presence of higher physical fitness. The present findings support the view that there are other pathways through which sport practice influences executive function beside the well-known physical fitness/executive function relationship. Alternatives include those linking executive function to the ability to perform coordinated movements in response to environmental cues and to the ability to perform cognitively challenging, strategic actions as needed in sport game situations. Also, the findings highlight that different executive functions are differently linked to physical fitness, motor fitness and sport proficiency. 


\section{Keywords}

\section{Cognition, Exercise, Cardiovascular Fitness, Coordinative Abilities, Game Skills}

\section{Introduction}

Research on the cognitive benefits of physical activity (PA) and fitness underwent a huge growth in the last decades (McMorris, in press; McMorris et al., 2009). As a consequence, the applied relevance of the exercisecognition interaction is entering official communications and recommendations of authoritative organizations and institutions advocating for health-enhancing PA (Council of the European Union, 2013; Garber et al., 2011). From a holistic perspective on health, it is indeed advocated that regular (i.e., chronic) physical exercise is effective not only for increasing or maintaining physical fitness (Garber et al., 2011), but also for promoting healthy brain development and aging (e.g., Gomez-Pinilla \& Hillman, 2013; Hillman et al., 2008; but see Young et al., 2015 and Verburgh, Königs et al., 2014 for a lack of meta-analytic confirmation calling for further research). There is large consensus that particularly the cardiovascular component of physical fitness is a correlate and is a determinant of the efficiency of higher-level cognitive function, the executive, involved in planning and control goal-directed behavior, flexibility and adaptability in thought and action essential for successful daily life functioning (Diamond, 2013).

Both behavioural and neuroscientific evidence supports this association (Khan \& Hillman, 2014; Pesce \& Ben-Soussan, in press; Tomporowski et al., 2011) with a disproportionally larger attention for preadolescent children (Chaddock, Pontifex et al., 2011) than for adolescents. High-fit children, as compared to low-fit ones, have differences at brain structural and cognitive functional levels (Chaddock et al., 2010; Chaddock, Hillman et al., 2011), higher efficiency in cognitive control and motor preparation, memory and learning (Berchicci et al., 2015; Pontifex et al., 2011; Raine et al., 2013), and higher academic performances (Howie \& Pate, 2012; Singh et al., 2012).

The majority of the still scarce adolescent studies found a positive association between PA and cognitive performance, most consistently when PA was of moderate-to-vigorous intensity as recommended to obtain physical fitness outcomes (Esteban-Cornejo et al., 2015) and cognitive performance relied on executive function (Booth et al., 2013). Nevertheless, the paucity of adolescent studies specifically focused on executive function may be responsible for the failure to provide meta-analytic confirmation of their association with habitual PA (Verburgh, Königs et al., 2014). Zooming into the neuroscientific approach to this issue, the few studies conducted with adolescents showed — similar to what obtained with children—brain structural and functional benefits of being highly fit (Herting \& Nagel, 2012, 2013; Herting et al., 2014; Stroth et al., 2009), but such positive association was not always paralleled by cognitive benefits at behavioural level (Herting \& Nagel, 2013). Behavioural evidence is also inconsistent as to whether in adolescence, the chronic exercise-cognition interaction is better reflected in the association of cognitive efficiency with daily PA level or with physical fitness, with contrasting evidence in favour of the first (Ruiz et al., 2010), or the latter (Pindus et al., 2015).

In sum, cross-sectional exercise and cognition studies with adolescents mostly focus on physical fitness as the only relevant outcome of habitual PA and sport practice that may be associated with efficient cognition. Other outcomes of physical and sports activities potentially linked to cognitive functioning through different pathways, such as motor fitness and skilled performance of strategic actions, are neglected. In fact, while quantitative parameters (intensity, duration, frequency) are responsible for the physical fitness outcomes of regular PA, qualitative parameters (exercise type, movement complexity) are responsible for motor fitness outcomes, that is the ability to perform coordinated movement actions.

Evidence that can help shed light on the latter issue emerges from research developed on a different track from that of exercise and cognition research. This line of research explores the interrelation between motor coordination and cognitive development at both the levels of behaviour and brain structure (Diamond, 2000). Overall, findings provide support for an association between motor coordination and executive function both in childhood (Niederer et al., 2011; Pangelinan et al., 2011; Roebers et al., 2014) and in adolescence (Rigoli et al., 2012a,b) and suggest shared mechanisms underpinning such relationship. Additionally, the above studies show differential associations between specific executive functions and aspects of physical or motor fitness. However, 
differences between executive function and physical/motor fitness measures employed in child and adolescent studies do not allow drawing conclusions on age-related differences.

In recent years, some authors (Best, 2010; Diamond, 2015; Moreau \& Conway, 2013; Pesce, 2012; Tomporowski et al., 2015) have proposed to go beyond the mere relationship between physical fitness and cognitive function, suggesting that also the cognitive demands inherent in sensorimotor learning and performing complex movement and sport tasks may be responsible for the observed positive association of PA and sports with higher-level cognition and metacognition. This represents a novel development in research on applied sport psychology, since studies on cognitive expertise in sport were mostly aimed at exploring cognitive predictors of successful sport performance for talent identification and optimization of sport-specific cognitive skills through training (Moran, 2009; Williams \& Ericcson, 2005).

The interest for the association between sport expertise and domain-general cognition, as executive function, that transfer to other life domains is recent (Voss, Kramer, Basak, Prakash, \& Roberts, 2010). Research on soccer has demonstrated that executive function efficiency is predictive of successful sport performance and varies as a function of the level of sport expertise in young adult athletes (Vestberg et al., 2012), as well as in preadolescent and adolescent youth players (Verburgh, Scherder et al., 2014). These findings cannot be generalized to all sport types, since different executive functions seem differentially modulated by different sporting expertise (Jacobson \& Matthaeus, 2014; Wang et al., 2013).

In the attempt to contribute unifying the views on the exercise and cognition interaction in adolescents that emphasize the role played by either health-related physical fitness (Herting \& Nagel, 2012; Pindus et al., 2015), or development- and learning-related motor fitness (Rigoli et al., 2012a,b), or performance-related sport skills (Verburgh, Scherder et al., 2014), the main aim of the present cross-sectional study was to evaluate whether physical and motor fitness and sport game skills are predictive of executive function efficiency in adolescence. Moreau (2015) has highlighted the bydirectionality of the relationship between motor experiences and higherlevel cognition and emphasized how the cognitive demands inherent in complex motor learning and sport tasks that impact motor fitness and sport proficiency may also lead to physiological changes in the brain that positively influence executive function efficiency. Thus, we hypothesized that not only physical fitness, but also the abilities and skills deriving from exercising goal-directed complex movements and strategic sport actions may be predictors of executive function efficiency.

Moreover, to our knowledge, no study in the exercise and cognition area has still evaluated whether physical fitness, motor fitness and sport skills interactively contribute to executive function efficiency in adolescence. Indeed from a sport psychological perspective, there is intriguing evidence that in adult athletes, physical fitness and sport expertise may interactively benefit executive function. Chan et al. (2011) performed a cross-sectional analysis of the inhibitory efficiency in open skill sports as a function of physical fitness level and sport-related cognitive expertise. They found that highly fit and expert athletes were best in executive function; however, when individuals were only averagely fit, cognitive expertise deriving from the extensive practice of a strategic sport was not associated with more efficient inhibitory function. This means that physical fitness acted as a moderator of the relationship between sport-related expertise and inhibitory efficiency. Thus, we tested a moderated prediction model to verify whether an interaction pattern between physical fitness and sport-related motor fitness and skills is predictive of executive function efficiency. This not limitedly to an athletes' population, but in the general population in the adolescent transition phase, when poor executive function may map onto health risk behaviours. Among core executive functions, we tested not only inhibition previously found (Chan et al. 2011) jointly sensitive to fitness and sport skill, but also working memory, as different aspects of memory resulted predicted by cardiovascular fitness in children and adolescents (Chaddock et al., 2010; Herting \& Nagel, 2013) and motor fitness in children (Niederer et al., 2011).

\section{Methods}

The research programme was authorized by Committees of the school involved, by students' parents, who gave written informed consent and by the Ethical Committee of Policlinico "Umberto I" of Sapienza University of Rome.

\subsection{Participants}

Five hundred and twenty-seven junior and senior high school students aged $12-15$ years (13.5 \pm 1.0 yrs), 340 
males and 187 females including 29 border-line students or students with intellective-relational disability volunteered. This sample was stratified by urban district and region, since it was composed by students belonging to six schools (20 classes) in a Northern and a Central region of Italy, from different districts which were representative of the variety of socio-cultural characteristics of respective urban population. Figure 1 shows the study flow diagram from the initial number of students involved to the actual number of data available for analysis (i.e., $\mathrm{n}=411,257$ male and 154 female students). As assessed by means of the IPAQ-A questionnaire (Hagströmer et al., 2008; Ottevaere et al., 2011, see below), 50\% were highly active, 27.5\% moderately active and $22.5 \%$ lowly active.

\subsection{Instruments and Procedures}

Students were administered field-based tests assessing (1) physical fitness (cardiovascular fitness and muscular power), (2) motor fitness (motor control and perceptual-motor adaptation ability), (3) game skills in team sport (decision making and tactical cooperation); they were also tested on (4) executive cognitive function (inhibition and working memory updating).

\subsubsection{Physical Fitness Assessment}

Participants were evaluated in (a) cardiorespiratory fitness, that is the ability of the circulatory and respiratory systems to supply oxygen to skeletal muscles during sustained PA, and (b) muscular power, that is the capability of the muscle to perform dynamic muscular contractions with maximal work output in shortest time. They are two complementary, main components of physical fitness (Garber et al., 2011).

Cardiorespiratory fitness. Participants performed the 20m shuttle run test (Léger \& Lambert, 1982). This field test allows estimating the maximum cardiovascular performance. Following standard recommendations (The Cooper Institute, 2010), participants were instructed to run a number of stages (levels), each lasting about 1 min and comprising a number of $20 \mathrm{~m}$ laps (shuttles), paced by auditory signals (beeps). At each stage, the required running speed increased, starting at a speed of $8.5 \mathrm{~km} / \mathrm{h}$ and increasing by $0.5 \mathrm{~km} / \mathrm{h}$ every minute. Maximal oxygen consumption $\left(\mathrm{VO}_{2 \max }\right)$ was estimated as: $[31.025+(3.238 \times$ velocity $)-(3.248 \times$ age $)+(0.1536 \times$ age $\times$ velocity)], where velocity $(\mathrm{km} / \mathrm{h})$ was inferred from the number of stages performed.

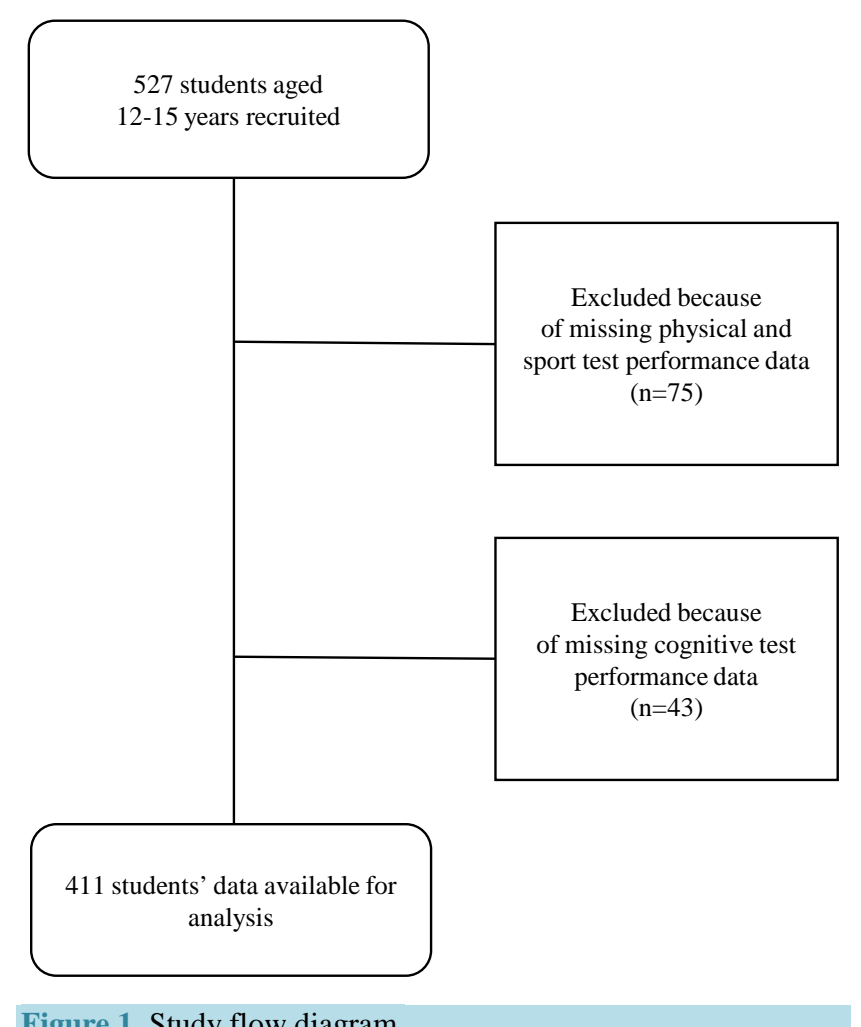

Figure 1. Study flow diagram. 
Muscular power. Maximal ball forward throw test was used to assess upper limb power. Participants performed three two-hand chest throw with a basketball as far as possible seated on a chair. The longest throw (in cm) was selected.

\subsubsection{Motor Fitness Assessment}

Participants were evaluated in (a) kinaesthetic discrimination, that is needed to finely tune the force output to the movement task demands, and (b) response orientation, that is the ability to quickly orient a movement action in space and time according to environmental cues. Kinaesthetic discrimination and response orientation are representative of the ability to finely control movements (motor control ability) and to appropriately adapt them in response to perceived changes in the environment (perceptual-motor adaptation ability), respectively (Mechling, 1999).

Kinaesthetic discrimination ability. Participants performed three ball forward throws at 50\% of individual maximum power output. The task conditions are the same as in the previous test, with the only difference that the participants were instructed to perform not at their maximum, but at $50 \%$ of their potential maximum. The average value of the three throws (in $\mathrm{cm}$ ) was computed. Before the first throw, participants were informed regarding the distance covered with their best maximal throw and after each 50\%-power throw, they received a feedback regarding the deviation from the maximum.

Response orientation ability. Participants performed the orientation shuttle run test belonging to a test battery for field evaluation of coordinative abilities validated by Hirtz and colleagues (1985) for children and adolescents and used also for Italian research in school settings (Gallotta et al., 2009). The participant was requested to run three times consecutively, as quickly as possible, from a start marker toward one of five numbered goal markers located behind them. The goal markers were $3 \mathrm{~m}$ apart from participant and $1.5 \mathrm{~m}$ apart from one another on an hypothetical circumference arc. The sequence of goal markings to be reached was not known in advance and the next marking number was announced when the participant returned to the start marker and touched it for the next run to begin without pausing. After demonstration, participants performed the test that was scored in seconds.

The rationale of choosing the above physical fitness and motor fitness measures is that they allowed us to disentangle fitness and coordination components. In fact, both Léger and Lambert's (1982) and Hirtz et al.'s (1985) shuttle run tests involve the same need to coordinate running forth and back, their difference being the aerobic and orientation requirements. Analogously, both ball forward throw tests involve the same technical skill, their difference being the muscular power and kinaesthetic discrimination requirements.

\subsubsection{Assessment of Decision Making and Tactical Cooperation Skills in Sport Games}

Participants were evaluated in game skills in team sport by means of the Game Performance Assessment Instrument for Invasion Games (GPAI, Mitchell et al., 2013). This is a tool to assess the capability to make appropriate strategic decisions (Decision Making) and to realize tactical cooperation (Support) under variable situational conditions and time pressure that characterize strategic team sports. Participants were observed during two halves of a handball game and evaluated on a five-point likert scale. Judgement criteria were: Appropriate choice when passing, as passing to unguarded teammates to set up a scoring opportunity (for Decision Making), and efficient off-the-ball movements to a position to receive a pass (or throw) from teammates, as when freeing oneself from the opponents and proceeding forwards toward the goal (for Support). On a subsample, two independent observers scored participants' decision making and support performance to evaluate the high inter-observer reliability (level of agreement: $r>.80$ ).

\subsubsection{Executive Function Assessment}

Participants performed the Random Number Generation (RNG) task (Towse \& Neil, 1998), a multidimensional test allowing to obtain differentiated indices of core executive functions involved in the generation of random sequences. They were instructed to verbally generate a random sequence of numbers between 1 and 9 to each beat of a 100-beat sequence with an inter-beat interval of 1 second. Prior to data collection by tape recording, participants performed a familiarization trial of 100 numbers. Both the omission of a number generation in correspondence of one tone and the production of numbers lower than 1 (0) or higher than 9 (10, 11 etc.) were considered errors and discarded. If errors exceeded a predefined maximum threshold of five, the entire block was repeated. The randomness of the sequence of numbers was measured by means of 18 different indices described 
by Towse and Neil (1998). Among those, six indices were selected as they reflect two components of executive function: inhibition of mental routines (turning point index [TPI], adjacency score [Adj], and runs score [Runs]) and working memory updating (redundancy score [Red], coupon score [Coupon], and mean repetition gap [MeanRG]).

The TPI is a ratio between the real frequency of turning points between ascending and descending series of numbers (e.g., the response change between the digits " 2 " and “5” in a hypothetical sequence "9, 7, 2, 5, 6, 8”) generated by the participant and their theoretical frequency in random responses. The Adj measures the relative frequency of pairs of adjacent ascending or descending numbers (e.g., 7 - 8 or 4 - 3) as compared to the total number of response pairs produced by the participant. The Runs score is an index of variability of the number of digits in successive ascending or descending runs.

The Red index reflects the unbalance of response alternative frequencies in a sequence that derives from a more frequent usage of given numbers than expected based on the theoretical frequency of each digit in random responses. The Coupon score measures the mean number of digits generated until the entire set of alternatives has been used. The MeanRG is the mean number of responses given until each digit reoccurs calculated for all digits throughout the whole sequence (e.g., in the sequence “2, 8, 4, 6, 2, 9, 7, 8", the digits " 2 " and "8” reoccur with a mean gap equal to 4).

\subsubsection{Assessment of Potential Covariates}

Self-reported PA level, emotional and social self-efficacy were obtained with questionnaires. The rationale for including these variables as covariates was that we aimed at disentangling the role played by age-related changes in PA level (Dumith et al., 2012), affective and social processing (Crone \& Dahl, 2012; Steinberg, 2005) that characterize adolescence from the relationship of interest linking fitness and sport skill factors to executive function.

Physical activity level. Participants were administered the International Physical Activity Questionnaire for Adolescents (IPAQ-A), a modified and slightly shortened (29 items) version of the long form (31 items) for adults that has been translated and validated in several languages including Italian for a multi-country adolescent study (Hagströmer et al., 2008; Ottevaere et al., 2011). PAQ questionnaires in general show an acceptable reliability, but a moderate at best validity due to overestimation and particularly unsatisfactory correlation with objective PA measures in children and younger adolescents (Helmerhorst et al., 2012). Nevertheless, the IPAQ-A was considered suitable for the purpose of the present study, as it has been proven able to detect, also at young adolescent age, those youths with highest PA level (Ottevaere et al., 2011), which might act as an age-related confounder.

Emotional and social self-efficacy. To evaluate participants' emotional and social skills, we used two unifactorial scales from the test battery developed by Pastorelli, Caprara, and Bandura (1998; Caprara, 2001) composed of 8 and 13 items assessing, on a seven-point likert scale, the perceived self-efficacy as regards the management of negative emotions and social skills, respectively.

\subsection{Statistical Analysis}

\subsubsection{Preliminary Computations}

Average indices of physical fitness, sport game skills, and core executive function (inhibition, working memory updating) were computed to limit the number of potential predictors and interaction terms between predictors and dependent variables to be introduced into regression models for main analysis.

Physical fitness. The number of stages performed in the shuttle run test and the length of the best maximal ball forward throw were standardized and averaged.

Motor fitness. To obtain an index of kinaesthetic discrimination ability, the absolute value of the difference between the mean of the three performed ball forward throws at $50 \%$ of individually maximum power output and the real $50 \%$ of the best maximal forward throw was computed. To obtain an index of response orientation ability that-similar to all other physical and cognitive performance indices-increases with increasing performance level, the seconds needed to perform the orientation shuttle run were standardized and reversed.

Inhibition and working memory updating. TPI, Adj and Runs were merged into an average index of inhibition and Red, Coupon and MeanRG into an average index of memory updating. Before averaging, all indices were standardized and Adj, Runs, Red and Coupon were reversed, since high levels of TPI, but low levels of Adj and Runs correspond to a high ability to inhibit and high levels of MeanRG, but low levels of Red and 
Coupon correspond to a high ability to update working memory.

Sport game skill. To obtain a summary index of strategic-tactical skills in sport game, we standardized and averaged Decision Making and Support scores.

Physical activity level. Data were cleaned, truncated and scored following standard recommendations and reference values (Ainsworth et al., 2000; The IPAQ group, 2015). The number of days per week and time periods per day spent walking, in moderate and vigorous activity recorded in each of the four domains of the questionnaire (school-related physical activity, transportation, housework and leisure time) were used for computing total PA. To eliminate outliers, minutes exceeding 180 per day were truncated to 180 . Data were then scored transforming them into energy expenditure estimates (METs). To calculate daily PA (MET-minutes per day), minutes reported in each activity level were multiplied by the given MET score for that activity. The overall Total PA MET-minutes/week score was computed as the sum of Total (Walking + Moderate + Vigorous) MET-minutes/week scores.

\subsubsection{Preliminary Analyses}

First, all physical fitness, motor fitness, sport game skill and executive function measures were submitted to correlational analysis (Pearson's $r$ ) to look for potential multicollinearities among PA-related factors and their association with executive function. To reduce the number of predictors of inhibition and working memory updating, a preliminary regression analysis model was run with all predictors entered simultaneously; in a second step, only those showing a standardised $\beta$ coefficient $>.1$ were entered. Thus, two multivariate regression analyses were initially performed with physical fitness, kinaesthetic discrimination, response orientation, decision making and support entered simultaneously as potential predictors of inhibition and working memory updating, respectively. In the case of inhibition, all predictors except kinaesthetic discrimination met the selection criterion. In the case of working memory updating, only physical fitness did.

\subsubsection{Main Analysis: Moderated Prediction Model}

The main question of the study regarded the individual and joint prediction of executive function accrued by PA-related factors. To address this issue, hierarchical regression analyses were run.

The analyses used to test moderated prediction (in the case of inhibition which was predicted by multiple factors in the preliminary multiple regression analysis) entailed the following steps.

1) Interaction variables were computed multiplying the predictors that met the selection criteria (i.e., physical fitness, response orientation and sport game skill) pairwise, thus obtaining three interaction terms: Physical Fitness $\times$ Response Orientation, Physical Fitness $\times$ Sport Game Skill and Response Orientation $\times$ Sport Game Skill.

2) Two separate hierarchical multiple regression analyses with forced entry method were run for the prediction of inhibition and working memory updating. Potential covariates (PA level, emotional and social self-efficacy) were statistically controlled for by entering them in a first block, while the individual predictors (physical fitness, response orientation, sport game skill) were entered in a second block and the interaction terms (Physical Fitness x Response Orientation, Physical Fitness x Sport Game Skill and Response Orientation x Sport Game Skill) in a third block.

3) If the regression results showed that the third block including the interaction terms added to the model a significant percentage of variance explained, post-hoc analyses of significant interactions were performed using simple slope testing (Aiken \& West, 1991).

\section{Results}

The preliminary correlation analysis showed that inhibition was weakly, but significantly correlated with response orientation $(\mathrm{r}=.23, p<.001)$ and sport game skill $(\mathrm{r}=.20, p<.001)$, while working memory updating with physical fitness $(\mathrm{r}=.21, p<.001)$. No collinearities $(\mathrm{r}>.80)$ emerged between physical fitness, kinaesthetic discrimination, response orientation, and sport game skills $(.41<\mathrm{r}<.63)$.

Table 1 shows significant results of individual hierarchical regression analyses for the two executive functions. With regard to the variance explained, the selected predictors contributed similarly to the prediction of executive function with $7 \%$ and $6 \%$ variance explanation for inhibition and working memory updating, respectively. The introduction of the interaction terms to the model applied to the inhibition variable added a small, but significant percentage of variance explained (4\%). 
Table 1. Hierarchical multiple regression analysis to predict inhibition and working memory updating performance. Tested predictors: physical fitness (cardiovascular fitness and muscle power), perceptual-motor adaptation ability (response orientation) and sport game skill (decision making and tactical cooperation) and their interaction after accounting for potential covariates (PA level, emotional and social self-efficacy).

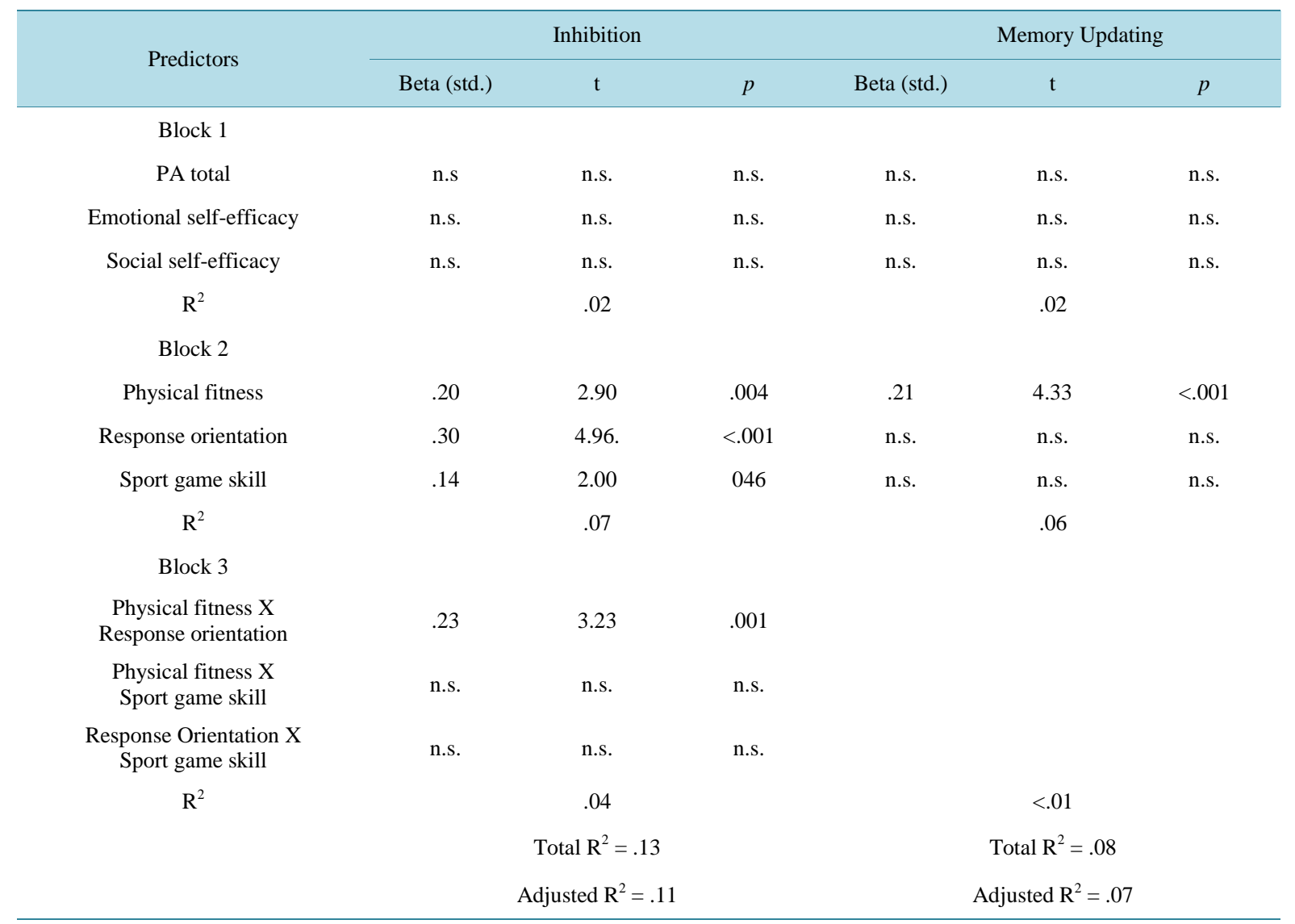

Notes: VIF statistics ranged between 1.0 and 1.4, thus allowing to exclude problems of multicollinearity.

Working memory updating was predicted only by physical fitness (Figure 2), while inhibition was positively predicted by all three predictors. However, only sport game skills was an individual predictor of inhibition (Figure 3), while physical fitness and response orientation interactively predicted it (Figure 4).

The prediction accrued by the Physical Fitness $\mathrm{x}$ Response Orientation interaction term in the second block indicates the presence of a moderated prediction. Since the results in the first regression block showed a stronger prediction of inhibition being accrued by response orientation than by physical fitness, post-hoc analyses were performed using response orientation as predictor of inhibition and physical fitness level (lower vs. higher) as a moderator of the response orientation-inhibition relationship. Figure 4 describes how the prediction of inhibition accrued by response orientation was moderated physical fitness. Inhibition was predicted by response orientation ability only in the presence of higher physical fitness, whereas no significant relationship between response orientation and inhibition emerged in the lower-fit group.

\section{Discussion}

It is surprising that although adolescence represents a critical period for brain development in which poor executive functioning - particularly low inhibitory efficiency —is associated with heightened risk behaviour (Pharo et al., 2011; Steinberg, 2005), exercise and cognition research has devoted least attention to the positive association between fitness or sport-related skills and executive function in this transition phase of life. The present study aimed at evaluating whether PA- and sport-related factors as physical and motor fitness and sport game skills are individual or joint predictors of adolescents' higher-level cognitive function, the executive. 


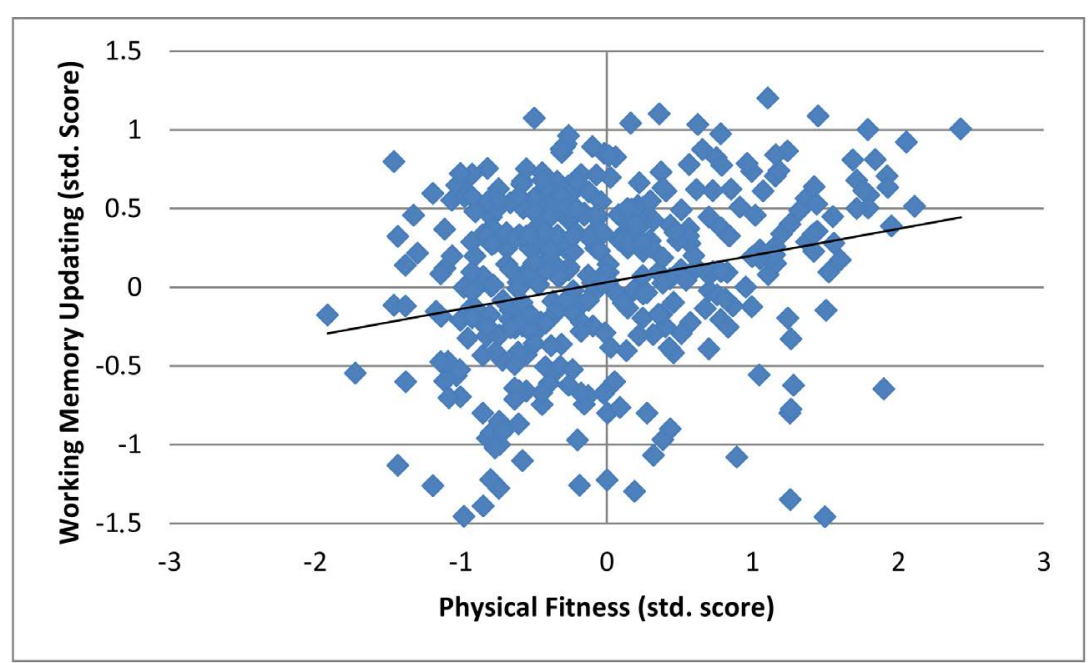

Figure 2. Working memory updating ability as a function of physical fitness (cardiovascular fitness and muscle power).

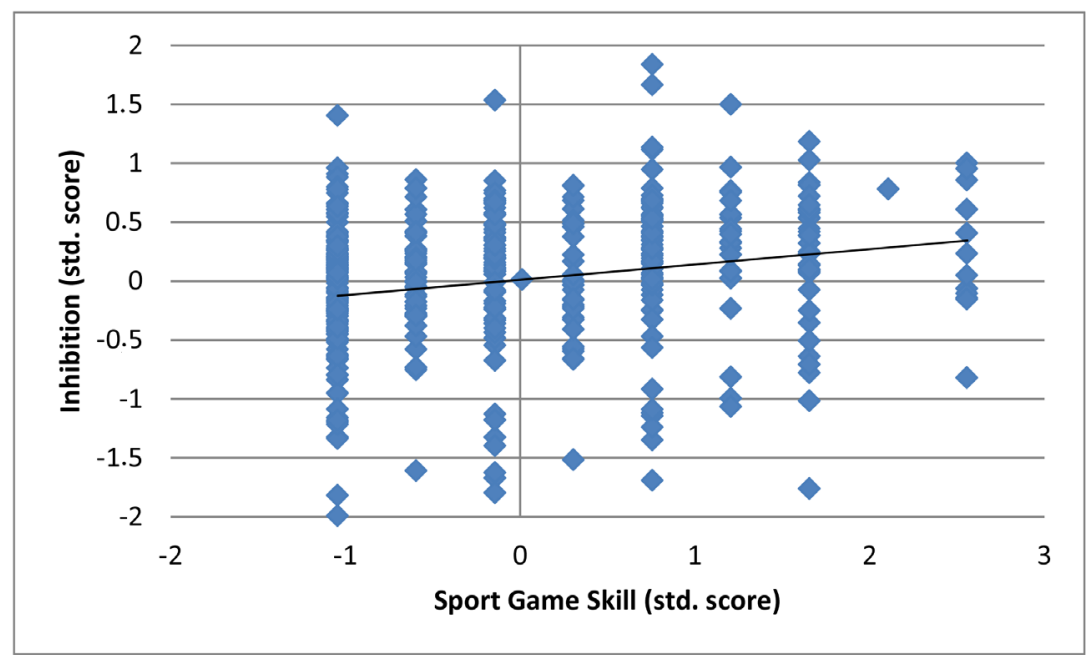

Figure 3. Inhibitory ability as a function of sport game skill (decision making and tactical cooperation).

According to recent claims, there may be different pathways through which the outcomes of PA and sport practice are associated with executive function. One is the well-known linkage between physical fitness and executive function; other putative pathways seem to be those linking executive function to the ability to perform well coordinated and adaptable movement actions (motor fitness) and to the ability to perform cognitively challenging, strategic game actions (Best, 2010; Diamond, 2015; Moreau \& Convay, 2013; Pesce, 2012; Tomporowski et al., 2015). Thus, we hypothesized that apart from the more commonly studied relationship between physical fitness and cognition in children (Chaddock, Pontifex et al., 2011; Khan \& Hillman, 2014 for reviews), with fewer evidence also in adolescents (Pesce \& Ben-Soussan, in press for a review), there might be further paths that link executive function with motor fitness and sport game skills. In sum, the results are consistent with this hypothesis and reveal that different executive functions are differently linked to physical and motor fitness and sport-related skills.

First, we found an association between physical fitness and the efficiency in manipulating and updating information in working memory (Figure 2). This finding seems to be consistent with the robust evidence obtained with preadolescent children that physical fitness benefits several aspects of memory (Raine et al., 2013 for a review). The behavioural advantage in memory tasks by high-fit children as compared to low-fit ones is explained 


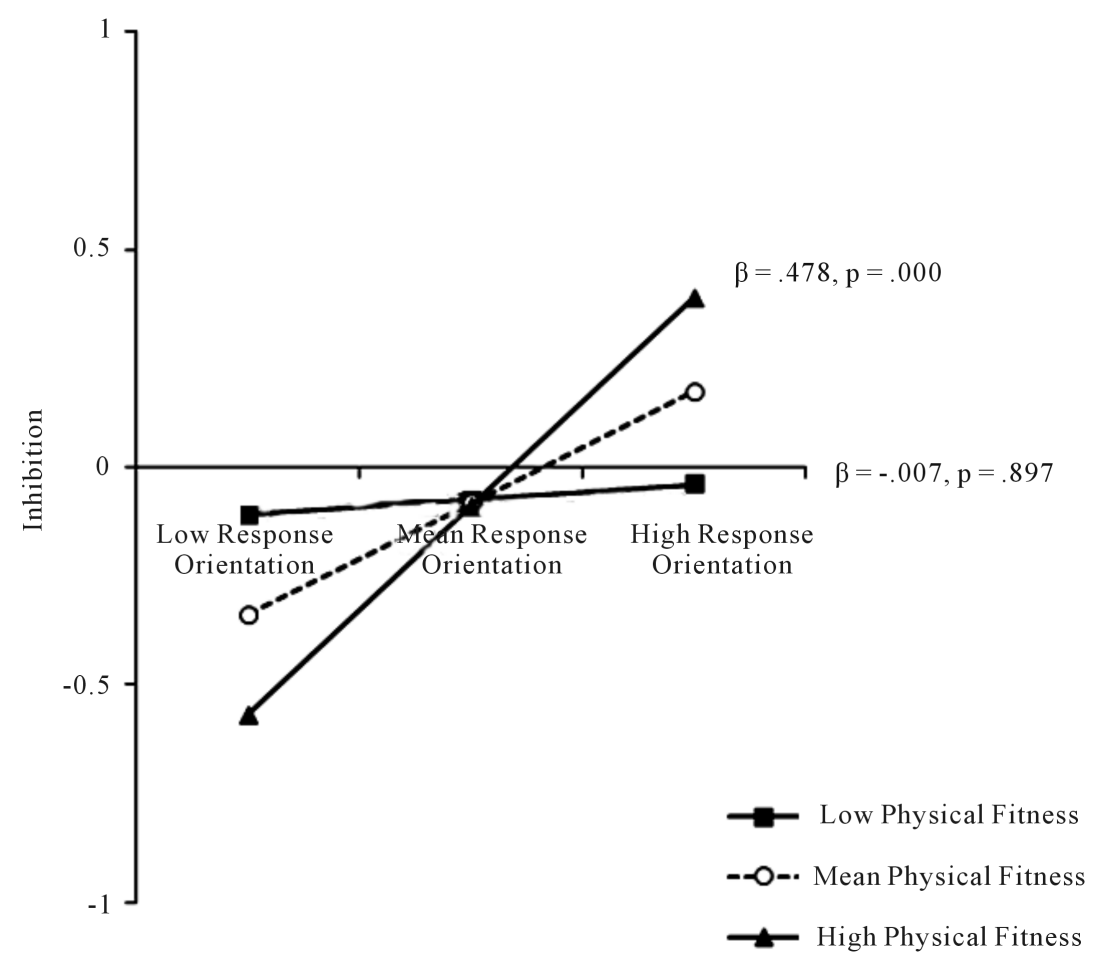

Figure 4. Inhibitory ability (std score) as a function of perceptual-motor adaptation ability (Response Orientation) in lower-fit and higher-fit adolescents: a moderated prediction.

by structural differences in the brain regions involved in memory processes, as a larger hippocampal volume (Chaddock et al., 2010; Chaddock, Hillman et al., 2011). Instead, research on chronic exercise effects on memory at adolescent age is less frequent and behavioural results are inconclusive, showing an association of cardiovascular fitness with some brain functions as visuospatial working memory (Herting \& Nagel, 2012), but an absence of correlation with other functions as memory control (e.g., Stroth, et al., 2009) or verbal associative memory (Herting \& Nagel, 2013). Also, there seem to be age-related differences. Niederer et al. (2011) found neither spatial, nor verbal working memory being predicted by cardiovascular fitness in pre-schoolers. Memory is an umbrella term involving several aspects and modalities of retention and recall of information. Specifically working memory, that is investigated in the present study, has a multifaceted nature, as it consists of three main components: the phonological loop, the visuospatial sketch pad, and the central executive. The three indices of working memory updating of the RNG task employed in the present study mainly tap the central executive component of updating (Towse \& Cheshire, 2007). This supports the hypothesis of the selective nature of the fitness-memory relationship at least during adolescence.

Moreover, it seems that working memory updating and inhibition are differently associated with different outcomes of PA and sport practice. While working memory efficiency was predicted by physical fitness (Figure 2), inhibitory efficiency was predicted by how adolescents were able to perform strategic actions in an interactive game situation (sport game skill, Figure 3) and to adapt their motor coordination in response to the perception of environmental cues (response orientation, Figure 4).

The association of perceptual-motor adaptation ability and strategic game skill with the efficiency of inhibitory function might reflect the cognitive advantage deriving from practicing movement and sport activities that have the characteristics of an enriched environment as it is conceived within an embodied framework of cognition (Moreau, 2015). This supports the suggestion that the cognitive effort required to coordinate complex movements and to cope with the cognitive demands of strategic sports might foster the development of domain-general inhibitory ability that is not only useful for the sport domain. Indeed, with only one exception (Jacobson \& Matthaus, 2014), studies performed with athletes practicing strategic sports showed that different facets of inhibition (interference control, inhibition of prepotent motor responses) are more efficient in experienced 
athletes (Verburgh, Scherder et al., 2014; Vestberg et al., 2012; Wang et al., 2013). From an applied psychology perspective, the aim can be either to identify cognitive factors that predict future successful sport performance (Vestberg et al., 2012), or to obtain information for designing sports training which may provide a potential clinical intervention for those who have difficulties in inhibitory control (Wang et al., 2013). Intriguing research has shown that executive function is sensitive to cognitive training at adolescent age independently of the presence of physical effort (Zinke et al., 2012). This supports the hypothesis that higher ability to suppress mental routines found in adolescents who were skilled in strategic and tactical sport game behaviour regardless of their physical fitness level (Figure 3) may result from the cognitive engagement inherent in PA and sport practice.

The major novelty of the present study is the moderated prediction model that emerged from the analysis of inhibition data (Figure 4). To our knowledge, studies that have addressed the association of motor fitness (i.e., motor coordination abilities and skills) with working memory or inhibition have done it without considering the role played by physical (cardiovascular or muscular) fitness (Rigoli et al., 2012a,b), or only examining the independent contribution of physical and motor fitness (Niederer et al., 2011). As Figure 4 shows, the relationship linking perceptual-motor adaptation ability and inhibitory efficiency is moderated by physical fitness: only higher-fit adolescents showed such a relationship. This result extends also to the adolescent population the findings by Chan and colleagues (2011) that sport-related cognitive expertise of athletes was a determinant of their inhibitory efficiency only when it was associated with a high level of physical fitness. When individuals were only averagely fit, cognitive expertise due to the extensive practice of a strategic sport requiring perceptual-motor adaptation ability and cognitive skills was no longer associated with inhibitory efficiency. Taken together, the present and Chan et al.'s (2011) findings are in line with the suggestion that a threshold level of fitness, contributing to the integrity of the neural "hardware", is necessary for exploiting the benefits deriving from exposure of the brain "software" to stimulation by the coordinative and cognitive complexity of the movement tasks (Pesce, 2012).

The present study has limitations that must be addressed. Primarily, the cross-sectional nature of the study does not allow to make conclusive inference of a causal relationship between PA- and sport-related factors (physical and motor fitness, sport game skills) and executive function efficiency. We cannot completely exclude that the found relationships are covariational in nature or mediated and moderated by factors that were not tested in the present research. Indeed, the limited amount of explained variance suggests that this may be the case and calls for caution when interpreting the data. Finally, we used only one multidimensional cognitive test tapping core executive functions. Given the emerging interest for metacognition in the study of the exercise-cognition interaction (Tomporowski et al., 2015), the future use of multiple tests extending from executive functions to metacognition assessment may further our understanding of this interaction in adolescents.

The present evidence, though cross-sectional in nature, has relevant applied implications. While the lifelong benefits of adolescent PA on health have been unequivocally proven (Hallal et al., 2006), the relatively low attention devoted to the association between physical/motor fitness and executive function at adolescent age calls for further research. Executive functions and their brain substrates experience a long maturation that extends until late adolescence (Blakemore \& Choudhury, 2006) and poor executive function may map onto health risk behaviours commonly associated with adolescence (Hall et al., 2006). Particularly, inhibition is a key element of self-regulation that can be critical in numerous aspects of daily life especially in adolescence. Thus, its unique relatedness to sport-related skills and to joint physical and motor fitness calls for intervention studies that capitalize on sport education to train inhibition within broader life skills programmes (Pesce et al., in press).

\section{Acknowledgements}

Rosalba Marchetti and her co-authors thank physical education teachers Giorgia Sanzo and Piero Leoni for their valuable contribution to the planning, organization and testing. In memory of Gabriella Ummarino, who enthusiastically agreed to participate with her students, but prematurely died.

\section{References}

Aiken, L. S., \& West, S. G. (1991). Multiple Regression: Testing and Interpreting Interactions. Newbury Park, CA: Sage.

Ainsworth B. E., Haskell, W. L., Whitt, M. C., Irwin, M. L., Swartz, A. M., Strath, S. J. et al. (2000). Compendium of Physical Activities: An Update of Activity Codes and MET Intensities. Medicine and Science in Sports and Exercise, 32, 498504. http://dx.doi.org/10.1097/00005768-200009001-00009 
Berchicci, M., Pontifex, M. B., Drollette, E. S., Pesce, C., Hillman, C. H., \& Di Russo, F. (2015). From Cognitive Motor Preparation to Visual Processing: The Benefits of Childhood Fitness to Brain Health. Neuroscience, 298, 211-219. http://dx.doi.org/10.1016/j.neuroscience.2015.04.028

Best, J. (2010). Effects of Physical Activity on Children's Executive Function: Contributions of Experimental Research on Aerobic Exercise. Developmental Review, 30, 331-351. http://dx.doi.org/10.1016/j.dr.2010.08.001

Blakemore, S. J., \& Choudhury, S. J. (2006). Development of the Adolescent Brain: Implications for Executive Function and Social Cognition. Child Psychology and Psychiatry, 47, 296-312. http://dx.doi.org/10.1111/j.1469-7610.2006.01611.x

Booth, J. N., Tomporowski, P. D., Boyle, J. M., Ness, A. R., Joinson, C., Leary, S. D., \& Reilly, J. J. (2013). Associations between Executive Attention and Objectively Measured Physical Activity in Adolescence: Findings from ALSPAC, a UK Cohort. Mental Health and Physical Activity, 6, 212-219. http://dx.doi.org/10.1016/j.mhpa.2013.09.002

Caprara, G. V. (2001). La valutazione dell'autoefficacia: Costrutti e strumenti. [Self-Efficacy Evaluation: Constructs and Instruments]. Trento: Erikson.

Chaddock, L., Erickson, K. I., Prakash, R. S., Kim, J. S., Voss, M. W., VanPatter, M. et al. (2010). A Neuroimaging Investigation of the Association between Aerobic Fitness, Hippocampal Volume and Memory Performance in Preadolescent Children. Brain Research, 1358, 172-183. http://dx.doi.org/10.1016/j.brainres.2010.08.049

Chaddock, L., Hillman, C. H., Buck, S. M., \& Cohen, N. J. (2011). Aerobic Fitness and Executive Control of Relational Memory in Preadolescent Children. Medicine and Science in Sports and Exercise, 43, 344-349. http://dx.doi.org/10.1249/MSS.0b013e3181e9af48

Chaddock, L., Pontifex, M. B., Hillman, C. H., \& Kramer, A. F. (2011). A Review of the Relation of Aerobic Fitness and Physical Activity to Brain Structure and Function in Children. Journal of the International Neuropsychological Society, 17, 1-11. http://dx.doi.org/10.1017/s1355617711000567

Chan, J. S. Y., Wong, A. C. N., Liu, Y., Yu, J., \& Yan, J. (2011). Fencing Expertise and Physical Fitness Enhance Action Inhibition. Psychology of Sport and Exercise, 12, 509-514. http://dx.doi.org/10.1016/j.psychsport.2011.04.006

Crone, E. A., \& Dahl, R. E. (2012). Understanding Adolescence as a Period of Social-Affective Engagement and Goal Flexibility. Nature Reviews Neuroscience, 13, 636-650. http://dx.doi.org/10.1038/nrn3313

Council of the European Union (2013). Council Recommendation on Promoting Health-Enhancing Physical Activity across Sectors. Brussels. http://ec.europa.eu/sport/library/news-documents/hepa_en.pdf

Diamond, A. (2000). Close Interrelation of Motor Development and Cognitive Development and of the Cerebellum and Prefrontal Cortex. Child Development, 71, 44-56. http://dx.doi.org/10.1111/1467-8624.00117

Diamond, A. (2013). Executive Functions. Annual Reviews of Psychology, 64, 135-168. http://dx.doi.org/10.1146/annurev-psych-113011-143750

Diamond, A. (2015). Effects of Physical Exercise on Executive Functions: Going beyond Simply Moving to Moving with Thought. Annals of Sports Medicine and Research, 2, 1011.

Dumith, S. C., Gigante, D. P., Domingues, M. R., \& Kohl, H. V. (2012). Physical Activity Change during Adolescence: A Systematic Review and a Pooled Analysis. International Journal of Epidemiology, 40, 685-698. http://dx.doi.org/10.1093/ije/dyq272

Esteban-Cornejo, I., Tejero-Gonzalez, C. M., Sallis, J. F., \& Veiga, O. L. (2015). Physical Activity and Cognition in Adolescents: A Systematic Review. Journal of Science and Medicine in Sport, 18, 534-539. http://dx.doi.org/10.1016/j.jsams.2014.07.007

Gallotta, M. C., Marchetti, R., Baldari, C., Guidetti, L., \& Pesce, C. (2009). Linking Coordinative and Fitness Training in Physical Education Settings. Scandinavian Journal of Medicine and Science in Sports, 19, 412-418. http://dx.doi.org/10.1111/j.1600-0838.2008.00796.x

Garber, C. E., Blissmer, B., Deschenes, M. R., Franklin, B. A., Lamonte, M. J., Lee, I. M. et al., American College of Sports Medicine (2011). Quantity and Quality of Exercise for Developing and Maintaining Cardiorespiratory, Musculoskeletal, and Neuromotor Fitness in Apparently Healthy Adults: Guidance for Prescribing Exercise. Position Stand. Medicine \& Science in Sports \& Exercise, 43, 1334-1359. http://dx.doi.org/10.1249/MSS.0b013e318213fefb

Gomez-Pinilla, F., \& Hillman, C. (2013). The Influence of Exercise on Cognitive Abilities. Comprehensive Physiology, 1, 403-428. http://dx.doi.org/10.1002/cphy.c110063

Hagströmer, M., Bergman, P., De Bourdeaudhuij, I., Ortega, F. B., Ruiz, J. R., Manios, Y. et al., The HELENA Study Group (2008). Concurrent Validity of a Modified Version of the International Physical Activity Questionnaire (IPAQ-A) in European Adolescents: The HELENA Study. International Journal of Obesity, 32, 342-348. http://dx.doi.org/10.1038/ijo.2008.182

Hall, P. A., Elias, L. J., \& Crossley, M. (2006). Neurocognitive Influences on Health Behavior in a Community Sample. Health Psychology, 25, 778-782. http://dx.doi.org/10.1037/0278-6133.25.6.778 
Hallal, P. C., Victora, C. G., Azevedo, M. R., \& Wells, J. C. (2006). Adolescent Physical Activity and Health: A Systematic Review. Sports Medicine, 36, 1019-1030. http://dx.doi.org/10.2165/00007256-200636120-00003

Helmerhorst, H. J., Brage, S., Warren, J., Besson, H., \& Ekelund, U. (2012). A Systematic Review of Reliability and Objective Criterion-Related Validity of Physical Activity Questionnaires. International Journal of Behavioral Nutrition and Physical Activity, 9, 103. http://dx.doi.org/10.1186/1479-5868-9-103

Herting, M. M., \& Nagel, B. J. (2012). Aerobic Fitness Relates to Learning on a Virtual Morris Water Task and Hippocampal Volume in Adolescents. Behavioural Brain Research, 233, 517-525. http://dx.doi.org/10.1016/j.bbr.2012.05.012

Herting, M. M., \& Nagel, B. J. (2013). Differences in Brain Activity during a Verbal Associative Memory Encoding Task in High- and Low-Fit Adolescents. Journal of Cognitive Neuroscience, 25, 595-612. http://dx.doi.org/10.1162/jocn_a_00344

Herting, M. M., Colby, J. B., Sowell, E. R., \& Nagel, B. J. (2014). White Matter Connectivity and Aerobic Fitness in Male Adolescents. Developmental Cognitive Neuroscience, 7, 65-75. http://dx.doi.org/10.1016/j.dcn.2013.11.003

Hillman, C. H., Erickson, K. I., \& Kramer, A. F. (2008). Be Smart, Exercise Your Heart: Exercise Effects on Brain and Cognition. Nature Review Neuroscience, 8, 58-65. http://dx.doi.org/10.1038/nrn2298

Hirtz, P., Arndt, H. J., Holtz, D., Jung, R., Ludwig, G., Schielke, E. et al. (1985). Koordinative Fähigkeiten im Schulsport (Coordinative Abilities in Physical Education). Berlin: Volk und Wissen Verlag.

Howie, E. K., \& Pate, R. R. (2012). Physical Activity and Academic Achievement in Children: A Historical Perspective. Journal of Sport and Health Science, 1, 160-169. http://dx.doi.org/10.1016/j.jshs.2012.09.003

Jacobson, J., \& Matthaeus, L. (2014). Athletics and Executive Functioning: How Athletic Participation and Sport Type Correlate with Cognitive Performance. Psychology of Sport and Exercise, 15, 521-527. http://dx.doi.org/10.1016/j.psychsport.2014.05.005

Khan, N. A., \& Hillman, C. H. (2014). The Relation of Childhood Physical Activity and Aerobic Fitness to Brain Function and Cognition: A Review. Pediatric Exercise Science, 26, 138-146. http://dx.doi.org/10.1123/pes.2013-0125

Léger, L. A., \& Lambert, J. (1982). A Maximal Multistage 20m Shuttle Run Test to Predict $\mathrm{VO}_{2 \max }$. European Journal of Applied Physiology and Occupational Physiology, 49, 1-12. http://dx.doi.org/10.1007/BF00428958

McMorris, T., Tomporowski, P. D., \& Audiffren, M. (Eds.) (2009). Exercise and Cognitive Function. West Sussex: Wiley and Sons.

McMorris, T. (In Press). Exercise-Cognition Interaction: A Neuroscience Perspective. Amsterdam: Elsevier.

Mechling, H. H. (1999). Coordinative Abilities. In Y. V. Auweele, F. Bakker, S. Biddle, M. Durand, \& R. Selier (Eds.), Psychology for Physical Educators (pp. 159-186). Champaign, IL: Human Kinetics.

Mitchell, S. A., Oslin, J. L., \& Griffin, L. L. (2013). Teaching Sport Concepts and Skills: A Tactical Games Approach for Ages 7 to 18 (3rd ed.). Champaign, IL: Human Kinetics.

Moran, A. (2009). Cognitive Psychology in Sport: Progress and Prospect. Psychology of Sport and Exercise, 10, 420-426. http://dx.doi.org/10.1016/j.psychsport.2009.02.010

Moreau, D. (2015). Unreflective Actions? Complex Motor Skill Acquisition to Enhance Spatial Cognition. Phenomenology and the Cognitive Sciences, 14, 349-359. http://dx.doi.org/10.1007/s11097-014-9376-9

Moreau, D., \& Conway, A. R. A. (2013). Cognitive Enhancement: A Comparative Review of Computerized and Athletic Training Programs. International Review of Sport and Exercise Psychology, 6, 155-183. http://dx.doi.org/10.1080/1750984X.2012.758763

Niederer, I., Kriemler, S., Gu, J., Hartmann, T., Schindler, C., Barra, J., \& Puder, J. J. (2011). Relationship of Aerobic Fitness and Motor Skills with Memory and Attention in Preschoolers (Ballabeina): A Cross-Sectional and Longitudinal Study. BMC Pediatrics, 11, 34.

Ottevaere, C., Huybrechts, I., De Bourdeaudhuij, I., Sjöström, M., Ruiz, J. R., Ortega, F. B. et al. (2011). Comparison of the IPAQ-A and Actigraph in Relation to $\mathrm{VO}_{2 \max }$ among European Adolescents: The HELENA Study. Journal of Science and Medicine in Sport, 14, 317-324. http://dx.doi.org/10.1016/j.jsams.2011.02.008

Pangelinan, M. M., Zhang, G., VanMeter, J. W., Clark, J. E., Hatfield, B. D., \& Haufler, A. J. (2011). Beyond Age and Gender: Relationships between Cortical and Subcortical Brain Volume and Cognitive-Motor Abilities in School-Age Children. Neuroimage, 54, 3093-3100. http://dx.doi.org/10.1016/j.neuroimage.2010.11.021

Pastorelli, C., Caprara G. V., \& Bandura, A. (1998). La misura dell’autoefficacia percepita in età scolare (Assessing Perceived Self-Efficacy in Schoolers). Età Evolutiva, 61, 28-40.

Pesce, C. (2012). Shifting the Focus from Quantitative to Qualitative Exercise Characteristics in Exercise and Cognition Research. Journal of Sport and Exercise Psychology, 34, 766-786.

Pesce, C., \& Ben-Soussan, T. D. (In Press). “Cogito ergo sum” or “ambulo ergo sum”? New Perspectives in Developmental 
Exercise and Cognition Research. In T. McMorris (Ed.), Exercise-Cognition Interaction: A Neuroscience Perspective. Amsterdam: Elsevier.

Pesce, C., Marchetti, R., Forte, R., Crova, C., Scatigna, M., Goudas, M., \& Danish, S. (In Press). Youth Life Skills Training: Exploring Outcomes and Mediating Mechanisms of a Group-Randomized Trial in Physical Education. Sport, Exercise and Performance Psychology, In Press.

Pindus, D. M., Davis, R. D., Hillman, C. H., Bandelow, S., Hogervorst, E., Biddle, S. J., \& Sherar, L. B. (2015). The Relationship of Moderate-to-Vigorous Physical Activity to Cognitive Processing in Adolescents: Findings from the ALSPAC Birth Cohort. Psychological Research, 79, 715-728. http://dx.doi.org/10.1007/s00426-014-0612-2

Pharo, H., Sim, C., Graham, M., Gross, J., \& Hayne, H. (2011). Risky Business: Executive Function, Personality, and Reckless Behavior during Adolescence and Emerging Adulthood. Behavioural Neuroscience, 125, 970-978. http://dx.doi.org/10.1037/a0025768

Pontifex, M. B., Raine, L. B., Johnson, C. R., Chaddock, L., Voss, M. W., Cohen, N. J. et al. (2011). Cardiorespiratory Fitness and the Flexible Modulation of Cognitive Control in Preadolescent Children. Journal of Cognitive Neuroscience, 23, 1332-1345. http://dx.doi.org/10.1162/jocn.2010.21528

Raine, L. B., Lee, H. K., Saliba, B. J., Chaddock-Heyman, L., Hillman, C. H. et al. (2013). The Influence of Childhood Aerobic Fitness on Learning and Memory. PloS ONE, 8, e72666. http://dx.doi.org/10.1371/journal.pone.0072666

Rigoli, D., Piek, J. P., Kane, R., \& Oosterlaan, J. (2012a). An Examination of the Relationship between Motor Coordination and Executive Functions in Adolescents. Developmental Medicine and Child Neurology, 54, 1025-1031. http://dx.doi.org/10.1111/j.1469-8749.2012.04403.x

Rigoli, D., Piek, J. P., Kane, R., \& Oosterlaan, J. (2012b). Motor Coordination, Working Memory, and Academic Achievement in a Normative Adolescent Sample: Testing a Mediation Model. Archives of Clinical Neuropsychology, 27, 766-780. http://dx.doi.org/10.1093/arclin/acs061

Roebers, C. M., Röthlisberger, M., Neuenschwander, R., Cimeli, P., Michel, E., \& Jäger, K. (2014). The Relation between Cognitive and Motor Performance and Their Relevance for Children's Transition to School: A Latent Variable Approach. Human Movement Science, 33, 284-297. http://dx.doi.org/10.1016/j.humov.2013.08.011

Ruiz, J. R., Ortega, F. B., Castillo, R., Martin-Matillas, M., Kwak, L., Vicente-Rodriguez, G. et al. (2010). Physical Activity, Fitness, Weight Status, and Cognitive Performance in Adolescents. The Journal of Pediatrics, 157, 917-922. http://dx.doi.org/10.1016/j.jpeds.2010.06.026

Singh, A., Uijtdewilligen, L., Twisk, J. W. R., van Mechelen, W., \& Chinapaw, M. J. M. (2012). Physical Activity and Performance at School: A Systematic Review of the Literature including a Methodological Quality Assessment. Archives of Pediatric Adolescent Medicine, 166, 49-55. http://dx.doi.org/10.1001/archpediatrics.2011.716

Steinberg, L. (2005). Cognitive and Affective Development in Adolescence. Trends in Cognitive Sciences, 9, 69-74. http://dx.doi.org/10.1016/j.tics.2004.12.005

Stroth, S., Kubesch, S., Dieterle, K., Ruchsowd, M., Heim, R., \& Kiefer, M. (2009). Physical Fitness, but Not Acute Exercise Modulates Event-Related Potential Indices for Executive Control in Healthy Adolescents. Brain Research, 1269, $114-124$. http://dx.doi.org/10.1016/j.brainres.2009.02.073

The Cooper Institute (2010). Fitnessgram/Activitygram Test Administration Manual. Champaign, IL: Human Kinetics.

The IPAQ Group (2015). Guidelines for Data Processing and Analysis of the International Physical Activity Questionnaire. http://www.ipaq.ki.se

Tomporowski, P. D., Lambourne, K., \& Okumura, M. S. (2011). Physical Activity Interventions and Children’s Mental Function: An Introduction and Overview. Preventive Medicine, 52, 3-9. http://dx.doi.org/10.1016/j.ypmed.2011.01.028

Tomporowski, P. D., McCullick, B., Pendleton, D. M., \& Pesce, C. (2015). Exercise and Children's Cognition: The Role of Exercise Characteristics and a Place for Metacognition. Journal of Sport and Health Science, 4, 47-55. http://dx.doi.org/10.1016/i.jshs.2014.09.003

Towse, J. N. (1998). On Random Generation and the Central Executive of Working Memory. British Journal of Psychology, 89, 77-101. http://dx.doi.org/10.1111/j.2044-8295.1998.tb02674.x

Towse, J. N., \& Cheshire, A. (2007). Random Number Generation and Working Memory. European Journal of Cognitive Psychology, 19, 374-394. http://dx.doi.org/10.1080/09541440600764570

Towse, J. N., \& Neil, D. (1998). Analyzing Human Number Generation Behavior: A Review of Methods Used and a Computer Program for Describing Performance. Behavior Research Methods, Instruments, and Computer, 30, 583-591. http://dx.doi.org/10.3758/BF03209475

Verburgh, L., Königs, M., Scherder, E. J., \& Oosterlaan, J. (2014). Physical Exercise and Executive Functions in Preadolescent Children, Adolescents and Young Adults: A Meta-Analysis. British Journal of Sports Medicine, 48, 973-979. http://dx.doi.org/10.1136/bjsports-2012-091441 
Verburgh, L., Scherder, E. J. A., van Lange, P. A., \& Oosterlaan, J. (2014). Executive Functioning in Highly Talented Soccer Players. PLoS ONE, 9, e91254. http://dx.doi.org/10.1371/journal.pone.0091254

Vestberg, T., Gustafson, R., Maurex, L., Ingvar, M., \& Petrovic, P. (2012). Executive Functions Predict the Success of TopSoccer Players. PLoS ONE, 7, e34731. http://dx.doi.org/10.1371/journal.pone.0034731

Voss, M. W., Kramer, A. F., Basak, C., Prakash, R. S., \& Roberts, B. (2010). Are Expert Athletes “Expert” in the Cognitive Laboratory? A Meta-Analytic Study of Cognition and Sport Expertise. Applied Cognitive Psychology, 24, 812-826. http://dx.doi.org/10.1002/acp.1588

Wang, C. H., Chang, C. C., Liang, Y. M., Shih, C. M., Chiu, W. S., Tseng, P. et al. (2013) Open vs. Closed Skill Sports and the Modulation of Inhibitory Control. PloS ONE, 8, e55773.

Williams, A. M., \& Ericcson, K. A. (2005). Perceptual-Cognitive Expertise in Sport: Some Considerations When Applying the Expert Performance Approach. Human Movement Science, 24, 283-307. http://dx.doi.org/10.1016/j.humov.2005.06.002

Young, J., Angevaren, M., Rusted, J., \& Tabet, N. (2015). Aerobic Exercise to Improve Cognitive Function in Older People without Known Cognitive Impairment. Cochrane Database of Systematic Reviews, 4, Article ID: CD005381. http://dx.doi.org/10.1002/14651858.cd005381.pub4

Zinke, K., Einert, M., Pfenni, L., \& Kliegel, M. (2012). Plasticity of Executive Control through Task Switching Training in Adolescents. Frontiers in Human Neuroscience, 6, 1-15. http://dx.doi.org/10.3389/fnhum.2012.00041 